\title{
A new study on Omeprazole spectrophotometric determination using 9- Fluorenylmethyl chloroformate as derivatizating agent
}

\begin{abstract}
An accurate, sensitive and simple method has been developed for spectrophotometric determination of omeprazole (OMZ) in its pharmaceutical formulation. The method based on derivatization of OMZ with 9- Fluorenylmethyl chloroformate (FMOC$\mathrm{Cl})$. All the reaction conditions were optimized, such as $\mathrm{pH}$, the buffer volume, concentration of the reagent, reaction temperature and time. The reaction was successfully promoted and the mechanism was postulated. The derivatization product has maximum absorbance at $217 \mathrm{~nm}$, and Beer's law was obeyed in the concentration range of 2.0 to $12.0 \mu \mathrm{g} / \mathrm{mL}$ with correlation coefficient 0.999 and limit of detection $0.364 \mu \mathrm{g} / \mathrm{mL}$. The method was validated with respect to accuracy, robustness and selectivity. The method successfully has been applied for determination of OMZ in the pharmaceutical formulation.
\end{abstract}

Keywords: omeprazole, FMOC-Cl, derivatization reaction, spectrophotometric determination

\section{Introduction}

Omeprazole

(OMZ) chemically

known

as 5 - M e thox y - 2 - [ [ ( $4-\mathrm{m}$ e th ox y - 3, 5 - d i m e thy $1-2$ pyridinyl)methyl]sulfinyl]-1H-benzimidazole (Figure 1), is one of irreversible proton pump $\left(\mathrm{H}^{+} / \mathrm{K}^{+}\right.$- ATPase $)$inhibitors that decrease acid secretion from gastric parietal cell, and it is also effective in treatment of Zollinger Ellison syndrome and preventing ulcer rebleeding, and recently it has been used as a potential anti-inflammatory agent to protect the gastric mucosa from the inflammation caused by Helicobacter pylori infection. The therapeutic importance of OMZ helped in development of many methods of determination in pharmaceutical formulations and biological samples. ${ }^{1,2}$<smiles>COc1ccc2[nH]c(S(=O)Cc3ncc(C)c(OC)c3C)nc2c1</smiles>

Figure I Chemical structure of OMZ.

Literature survey revealed that, there are several publication of omeprazole quantitative determination either individually or combined dosage form using various techniques, for instance, LCMS/MS procedure for determination in drugs and metabolites in biological liquids such as urine and plasma, UPLC with UV detection method for determination of omeprazole in omeprazole magnesium blend, ${ }^{3}$ FT-IR spectroscopic determination of omeprazole in combined dosage form, ${ }^{4}$ RP-HPLC methods of determination, ${ }^{5-9}$ HPLC quantitative methods of determination, ${ }^{10-14}$ Capillary electrophoresis, ${ }^{15}$ electrochemical methods, ${ }^{16-19}$ spectrofluorometric methods ${ }^{20}$ and spectrophotometric methods. ${ }^{21-27}$ However, some methods have low sensitivity and accuracy.

Among these techniques UV-Visible spectrophotometry is one of the most frequently employed techniques in pharmaceutical analysis, ${ }^{28}$
Volume 8 Issue 2 - 2019

Iman Ahmed Alamin, Abdalla Ahmed Elbashir

Department of Chemistry, University of Khartoum, Sudan

Correspondence: Abdalla Ahmed Elbashir, University of Khartoum, Faculty of Science, Department of Chemistry, Khartoum I I I I, Sudan, Tel +249566 I43 I43 I,

Email aaelbashir@uofk.edu

Received: January 28, 2019 | Published: March 20, 2019 it is a convenient technique due to its simplicity, cost effective, sensitivity, and wide availability in laboratories.

Derivatization is a chemical reaction that yields a new product. It is often required in order to increase sensitivity or selectivity, and can be achieved by specific detection such as fluorescence or absorption in specific wavelength, and it can be induced by organic, electrochemical, or displacement (nucleophilic or electrophilic) reactions using specific reagents, one of these reagents is 9- Fluorenylmethyl chloroformate (FMOC-Cl), it is used to derivatize primary, secondary amines, and phenolic hydroxyl moieties by nucleophilic substitution reaction, and it is also applied in the derivatization of aminoglycosides such as gentamycin. ${ }^{29}$ Determination of pharmaceuticals has also been reported using this reagent, it has been used to improve the detection limit and accuracy. ${ }^{30}$

Even though omeprazole methods of determination have been extensively studied, the development and validation of simple, accurate, and alternative method of omeprazole determination has been carried out in the present work, in order to overcome other methods disadvantages.

\section{Experimental}

\section{Apparatus}

The spectrum of the reaction product was measured, the optimum condition was determined and the validation characters were calculated using UV-1800 Shimadzu (UV spectrophotometer) with spectrum region $190-800 \mathrm{~nm}$.

\section{Preparation of reagents and solutions}

All reagents and chemicals are with analytical grade, distilled water was used in all experiments.

\section{Stock standard solution}

OMZ stock powder (99.9\%) was obtained kindly from Amipharma Laboratories (Sudan), $100 \mu \mathrm{g} / \mathrm{mL}$ solution of $\mathrm{OMZ}$ in acetonitrile 
(98\%) was prepared and kept in refrigerator at $4^{\circ} \mathrm{C}$, then the working standards were prepared freshly by taking appropriate volume of stock solution.

\section{9-Fluorenylmethyl chloroformate}

FMOC-Cl was obtained from Sigma-Aldrich (St. Louis, USA) $(97 \%), 100 \mu \mathrm{g} / \mathrm{mL}$ solution was prepared in acetonitrile (98\%), then appropriate volumes were taken to prepare fresh working standards.

\section{Buffer solution}

Boric acid (97\%), Potassium chloride (98\%) and Sodium hydroxide $(99.9 \%)$ were obtained from SDFCL (Mumbai) and used to prepare borate buffer solution (BBS) $0.2 \mathrm{molL}^{-1}$ with different $\mathrm{pH}$ values.

\section{Sample solution}

The content of 10 capsules of OMZ (Omiz 20mg - AmipharmaSudan) were evacuated and mixed, then an appropriate weight was taken, dissolved in $1.0 \mathrm{ml}$ of sodium hydroxide, sonicated for 10 minutes, then completed to the mark with acetonitrile to prepare $100 \mu \mathrm{g} / \mathrm{mL}$ solution.

\section{Results and discussion}

Derivatization reaction of $\mathrm{OMZ}$ using $\mathrm{FMOC}-\mathrm{Cl}$ is an alternative method of determination, which increase the sensitivity in the ultraviolet region. In the present work the effectiveness of derivatization reaction between FMOC-Cl and $\mathrm{OMZ}$ studied with accordance to the optimum conditions, including the $\mathrm{pH}$, buffer volume, FMOC-Cl concentration, temperature and time of the reaction.

\section{Derivatization procedure}

To ensure the formation of the derivatization product by the proposed method, some experiments were performed as follows:

a. The spectrum of $10.0 \mu \mathrm{g} / \mathrm{mL} \mathrm{OMZ}$ in the reaction media $(2.5 \mathrm{ml}$ of $0.2 \mathrm{molL}^{-1}$ borate buffer $\mathrm{pH}=8.0$ and $6.5 \mathrm{ml}$ of acetonitrile) was measured in the range of 200 to $400 \mathrm{~nm}$.

b. The spectrum of $5.0 \mu \mathrm{g} / \mathrm{mL}$ FMOC-Cl in the reaction media $(2.5 \mathrm{ml}$ of $0.2 \mathrm{molL}^{-1}$ borate buffer $\mathrm{pH}=8.0$ and $6.5 \mathrm{ml}$ of acetonitrile) was measured in the range of 200 to $400 \mathrm{~nm}$.

c. $1.0 \mathrm{ml}$ of $\mathrm{OMZ} 100 \mu \mathrm{g} / \mathrm{mL}$ was transferred to $10 \mathrm{ml}$ volumetric flask containing $2.5 \mathrm{ml}$ of $0.2 \mathrm{molL}^{-1}$ borate buffer $\mathrm{pH}=8.0$, then $0.5 \mathrm{ml}$ of FMOC-Cl $100 \mu \mathrm{g} / \mathrm{mL}$ was added and, heated to $60^{\circ} \mathrm{C}$ and mixed for 2 min using vortex mixer, then completed to the mark by acetonitrile. The spectrum of the mixture was directly measured in the range of $200-400 \mathrm{~nm}$.

\section{Optimization of the reaction}

To ensure the effectiveness of the reaction, the spectra of the OMZ in the medium, FMOC-Cl in the medium, and the reaction product was compared (Figure 2). In the reaction optimization, some variables have been taken in the consideration that have great effect on the absorbance in order to get the higher, stable, and clear peak with good yield of product and fast preparation procedure of derivatization (Table 1).

$5.0 \mu \mathrm{g} / \mathrm{mL}$ FMOC-Cl spectrum in the reaction medium has three absorbance peaks $(206,264,300 \mathrm{~nm})$, the $10.0 \mu \mathrm{g} / \mathrm{mL}$ of $\mathrm{OMZ}$ has maximum absorbance 0.164 at $300 \mathrm{~nm}$, and the derivatization product profile has two absorbance region $(217 \overline{\text { and }} 300 \mathrm{~nm})$ and it is clearly observed that the absorbance peak has increased.

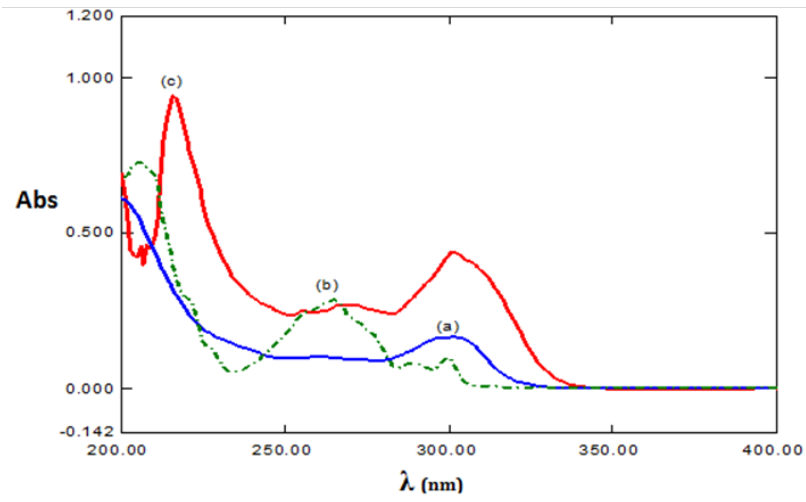

Figure 2 Absorption spectra of: (a) OMZ $10.0 \mu \mathrm{g} / \mathrm{mL}$ (blue line), (b) FMOC$\mathrm{Cl} 5.0 \mu \mathrm{g} / \mathrm{mL}$ (green line), (c) OMZ and FMOC-Cl reaction product (red line).

Table I The optimization conditions of the proposed method

\begin{tabular}{ll}
\hline Condition & Range \\
\hline $\mathrm{pH}$ & $6.0-10.0$ \\
Borate buffer volume $(\mathrm{mL})$ & $1.0-2.5$ \\
FMOC-Cl concentration $\mu \mathrm{g} / \mathrm{mL}$ & $5.0-25.0$ \\
Reaction Temperature $\left({ }^{\circ} \mathrm{C}\right)$ & $27.0-70.0$ \\
Time of the reaction $(\mathrm{min})$ & $0.0-25$ \\
\hline
\end{tabular}

\section{Effect of the $\mathrm{pH}$}

$\mathrm{pH}$ of the medium affects both FMOC-Cl and OMZ, in the alkaline media OMZ generates nucleophile and so the nucleophilic substitution reaction with FMOC-Cl will take a place, ${ }^{29}$ also OMZ decomposes in the acidic media. $\mathrm{pH}$ values control the derivatization and the hydrolysis products; the formation of FMOC-OMZ and FMOC-OH are produced simultaneously, and the concentration of FMOC-OMZ decreased as FMOC-OH formed. in present procedure variation of $\mathrm{pH}$ values (from 6.0 to 10.0 ) of BBS $0.2 \mathrm{molL}^{-1}$ revealed that the FMOC-OMZ production increased gradually till $\mathrm{pH} 8.0$ [the highest absorbance value]and decreased after that due to FMOC-OH quick formation (35), so $\mathrm{pH} 8.0$ has been chosen as optimum (Figure 3a).

\section{Effect of the buffer volume}

The influence of $0.2 \mathrm{molL}^{-1} \mathrm{BBS}$ volume $(1.0$ to $2.5 \mathrm{ml})$ on the nucleophilic substitution reaction was investigated, the absorbance increase with increasing of buffer volume which promotes the amine group reactivity and stabilize the solubility of derivatization product in the acetonitrile (31). it has been found that $2.0 \mathrm{ml}$ is the optimum volume to achieve maximum buffering capacity and facilitate the substitution. The absorbance peak decreases by increasing the volume buffer solution. This is properly due to the increase of hydroxide ion that retard the reaction between FMOC-Cl and OMZ and fasten the formation of FMOC-OH ${ }^{1}$ (Figure 3b).

\section{Effect of FMOC-Cl concentration}

The reagent concentration has great effect on the product formation, so the variation in the FMOC-Cl concentration was studied in the range ( 5.0 to $25 \mu \mathrm{g} / \mathrm{mL})$. The result revealed that at lower concentration decrease the probability of the reaction, so lower absorbance attained. As increasing the concentration, the absorbance 
increases and reach the maximum at $20.0 \mu \mathrm{g} / \mathrm{mL}$ where the reaction is completed, then decreases due to hydrolysis reaction of excess reagent that convert to $\mathrm{FMOC}^{-\mathrm{OH}^{31}}$ (Figure $3 \mathrm{c}$ ).

\section{Effect of temperature and time of the reaction}

OMZ is sensitive and decomposes at high temperature, ${ }^{32}$ the effect of the reaction temperature was investigated, and the result showed that the absorbance increases while the temperature increase in the range of $\left(29-60^{\circ} \mathrm{C}\right)$, then decreases due to the decomposition of OMZ (Figure 4a). The reaction time effect is important to ensure the completion of the substitution reaction, the spectrum of the product in the time ( 0 to $20 \mathrm{~min}$ ) revealed that the variation of the absorbance was not significant (about 0.2 ), so that direct measurement was determined as optimum (Figure $4 \mathrm{~b})$.
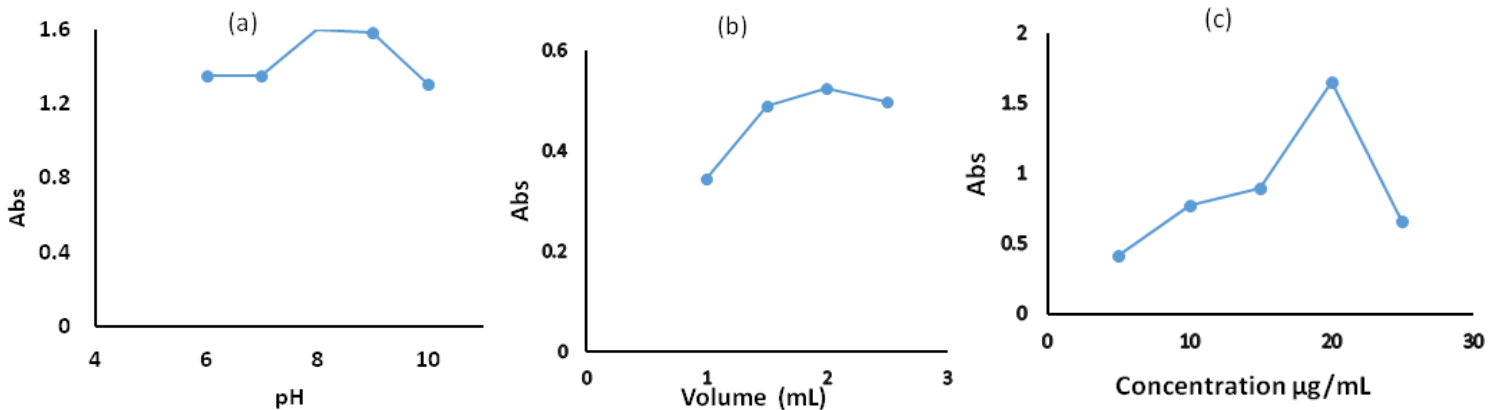

Figure 3 Effect of the optimization parameters on the derivatiztion reaction, (a): $\mathrm{pH}$ ranges 6.0 to 10 , (b) $\mathrm{BBS} 0.2 \mathrm{molL}^{-1}$ volumes 1.0 to $2.5 \mathrm{~mL}$, (c): $\mathrm{FMOC}-\mathrm{Cl}$ concentration in the range 5.0 to $25.0 \mu \mathrm{g} / \mathrm{mL}$.
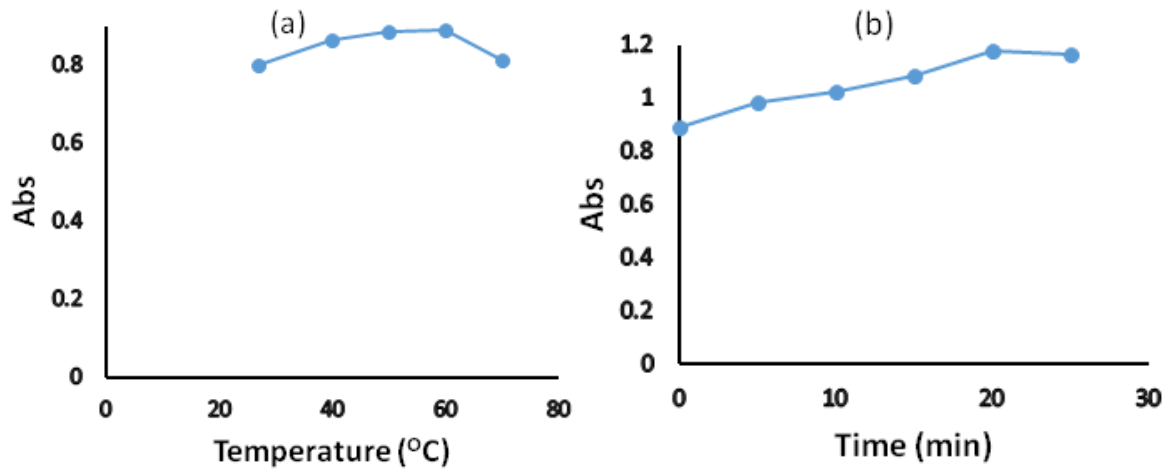

Figure 4 Effect of reaction temperature and time on the reaction product of $\mathrm{OMZ}(10.0 \mu \mathrm{g} / \mathrm{mL})$ and $\mathrm{FMOC}-\mathrm{Cl}(10.0 \mu \mathrm{g} / \mathrm{mL})$.

\section{Propsed mechanism of the reaction}

FMOC-Cl reacts with primary and secondary amines by nucleophilic substitution in two minutes at buffer $\mathrm{pH} 8.0$ giving stable derivative, and it combines with imidazole ring of amino compounds. ${ }^{28} \mathrm{OMZ}$ has imidazole moiety that could react to form FMOC-Cl derivative (Scheme 1).

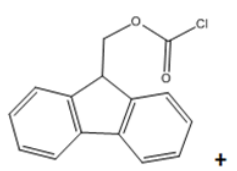<smiles>COc1ccc2[nH]c(S(C)=O)nc2c1</smiles>

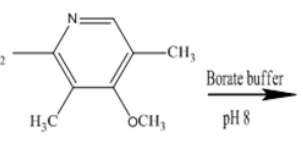

FMOC-CI OMz

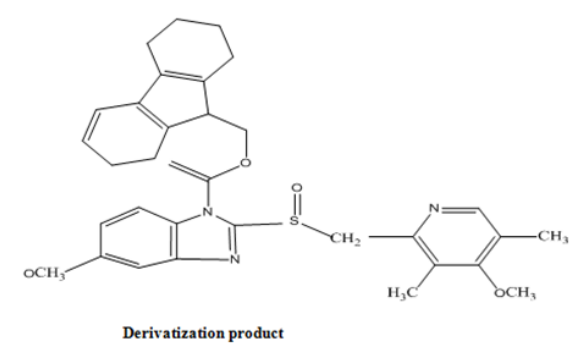

Scheme I Proposed derivatization reaction pathway.

\section{Method validation}

\section{Linearity, limit of detection (LOD) and limit of quantification (LOQ)}

Calibration curve was performed using different concentration of OMZ in the range $2.0-12.0 \mu \mathrm{g} / \mathrm{mL}$, with correlation coefficient $\mathrm{r}^{2}$ 0.999 and intercept 0.1456 (Figure 5), the intercept is not comparable in magnitude to the standard error and the $\mathrm{r}^{2}$ value is low when the curve line is forced to cross the origin, so the line should not across the base $[0,0](36)$, also the intercept has relatively large value, it might be due to unstable absorbance that produced from lower concentrations $[1.0 \mu \mathrm{g} / \mathrm{mL}]$ which considered as noise. very low concentrations [lower than $1.0 \mu \mathrm{g} / \mathrm{mL}$ ] have lower absorbance than the blank, and give negative intercept value, so $2.0 \mu \mathrm{g} / \mathrm{mL}$ used as starting concentration for calibration curve. Molar absorptivity $\epsilon$ is found to be $2.89 \times 10^{4}$ $\mathrm{Lmol}^{-1} \mathrm{~cm}^{-1}$, and Sandell's sensitivity $=0.5139 \mu \mathrm{g} / \mathrm{mL} / \mathrm{cm}^{2}$.

The minimum level of the analyte that can be detected (LOD) is calculated using the following equation

\section{$3.3 \mathrm{~s} / \mathrm{k}$}

Where $\boldsymbol{s}$ is the standard deviation of the intercept, $\boldsymbol{k}$ is the slope of calibration curve, according to this equation the limit of detection found to be $0.364 \mu \mathrm{g} / \mathrm{mL}$. 


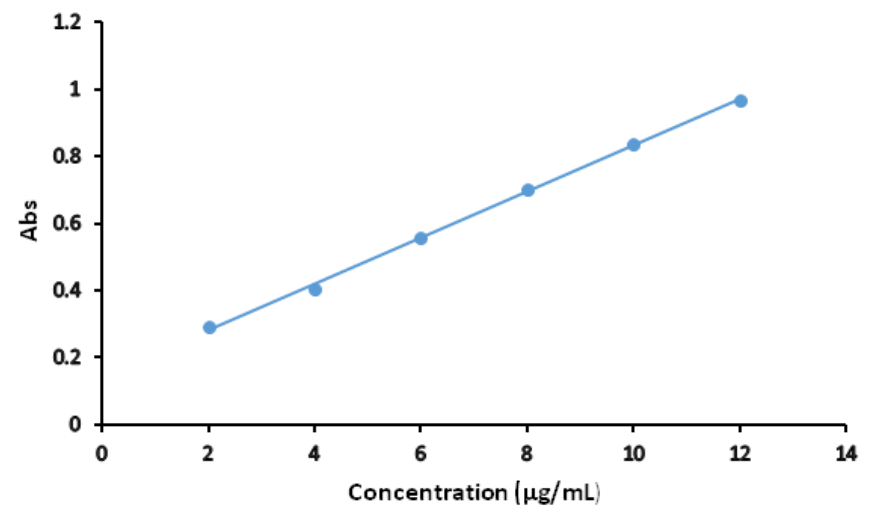

Figure $\mathbf{5}$ The calibration curve constructed in the optimum conditions in the range 2.0 to $12.0 \mu \mathrm{g} / \mathrm{mL}$.

The limit of quantification (LOQ) is the lowest concentration of the analyte that can be measured with accepted accuracy and precision ${ }^{33}$ is calculated by the following equation:

$10 \mathrm{~s} / \mathrm{k}$

The calculated LOQ for this method found to be $1.214 \mu \mathrm{g} / \mathrm{mL}$ (Table 2).

The proposed spectrophotometric method that applied for OMZ determination was compared to other validated methods, the

Table 3 Comparison of OMZ quantification using UV-Vis Spectrophotometer with different derivatization methods

\begin{tabular}{llllll}
\hline Reagent & Linearity range $(\mu \mathrm{g} / \mathrm{mL})$ & Regression equation & $\mathbf{r}^{2}$ & LOD $(\mu \mathrm{g} / \mathrm{mL})$ & LOQ $(\mu \mathrm{g} / \mathrm{mL})$ \\
\hline This study (FMOC-Cl) & $2.0-12.0$ & $\mathrm{Y}=0.0688 x+0.1456$ & 0.999 & 0.364 & 1.214 \\
DNFB $^{\mathrm{a}}$ & $5.0-40.0$ & $\mathrm{Y}=0.02 \mathrm{x}+0.074$ & 0.999 & 1.48 & $4.5 \mathrm{I}$ \\
DCNQ $^{\mathrm{b}}$ & $5.0-50.0$ & $\mathrm{Y}=0.003 x+0.0105$ & 0.999 & 3.27 & 9.92 \\
BROM $^{\mathrm{b}}$ & $20.0-225.0$ & $\mathrm{Y}=0.0039 \mathrm{x}+0.0072$ & 0.999 & 6.21 & 18.82 \\
\hline
\end{tabular}

a reference ${ }^{34}$, ${ }^{b}$ reference ${ }^{2}$

Table 4 Recovery of the proposed method

\begin{tabular}{|c|c|c|c|c|}
\hline Sample $(\mu g / m L)$ & Added $(\mu \mathrm{g} / \mathrm{mL})$ & Found $(\mu \mathrm{g} / \mathrm{mL})$ & Recovery* \pm RSD (\%) & Relative error (Er\%) \\
\hline 4 & 4 & 8.03 & $100.33 \pm 2.86$ & 0.33 \\
\hline 4 & 6 & 10.11 & $101.10 \pm 1.01$ & 1.01 \\
\hline
\end{tabular}

*The values are mean of three determinations.

\section{Robustness}

The robustness of the method was studied to evaluate the effect of small variation in some parameters upon its analytical performance. The parameters were $\mathrm{pH}$, temperature of the reaction and reagent concentration. The recovery was calculated each time and there was no significant effect was observed except at high temperature (Table $5)$.

\section{Selectivity}

To evaluate the effect of frequently founded species (excipients) within OMZ pharmaceutical formulation, a study containing these species was carried out. A solution of $12.0 \mathrm{mgL}^{-1}$ of $\mathrm{OMZ}$ standard spiked with different species under the optimum conditions. The results found were the same as the obtained result in the calibration, indicating that there is no effect of interference. comparison indicates that this method is more sensitive and accurate than the others ${ }^{2,34}$ in the same concentration range (Table 3).

Table 2 Summery of statistical data of the linear calibration curve

\begin{tabular}{ll}
\hline Parameter & Value \\
\hline Linear range $(\mu \mathrm{g} / \mathrm{mL})$ & $2.0-12.0$ \\
LOD $(\mu \mathrm{g} / \mathrm{mL})$ & 0.364 \\
LOQ $(\mu \mathrm{g} / \mathrm{mL})$ & 1.214 \\
Slope & 0.0688 \\
Intercept & 0.1456 \\
Correlation coefficient $\left(\mathrm{r}^{2}\right)$ & 0.999 \\
Molar absorpativity $(\epsilon) \mathrm{L} \mathrm{mol}^{-1} \mathrm{~cm}^{-1}$ & $2.889 \times 10^{4}$ \\
Sandell's sensitivity & 0.5139
\end{tabular}

\section{Accuracy and precision}

The accuracy and precision of the proposed method were carried out by using three different concentrations with three replicates. Accuracy was determined by calculating the recovered value and the percentage relative error (Er \%) (Table 4), and the precision was determined using pure standard by calculating the percentage relative standard deviation (RSD \%). The results revealed that the proposed method has good level of accuracy and precision. ${ }^{35}$ 


\section{Conclusion}

In this work, the product of the derivatization reaction between $\mathrm{OMZ}$ and FMOC-Cl has been utilized to develop a simple accurate and sensitive spectrophotometric method for OMZ analysis in pharmaceutical formulation, the derivatization reaction was optimized, the suggested mechanism was postulated and the method was validated with accordance of linearity, accuracy, selectivity and other validation character. The proposed method is superior to other spectrophotometric methods using derivatization, ${ }^{2,34}$ making it suitable for use in quality control laboratories.

\section{Acknowledgments}

None.

\section{Conflicts of interest}

The author declares that there is no conflicts of interest.

\section{References}

1. Ashour S, Bayram R. Validated Spectrophotometric Method for Determination of some Benzimidazole Derivatives in pharmaceutical formulations using 1,2-naphthoquinone-4-sulphonate. International Research Journal of Pure \& Applied Chemistry. 2013;3(2):118-132.

2. Alkahtania S, Mahmoud A, Samer S Abu Al-Rubb Novel Analytical Study for The Charge-Transfer Reactions of Omeprazole with 2,3-Dichloro-Naphthoquinone and 2,3,5,6-Tetrabromo- 1,4Benzoquinone: Application for The Development of Microwell Assay of Omeprazole. Journal of Advances in Chemistry. 2018;15(2):60996115.

3. Prasad P, Bhuvaneswari K. Different analytical techniques for quantitative analysis of omeprazole in bulk and pharmaceutical dosage forms. World Journal of Pharmacy and Pharmaceutical Sciences. 2015;4(7):276-284.

4. P Ravi Prasad, K Bhuvaneswari, Murarilal, et al. Quantitative determination of domperidone and omeprazole in combined dosage form by FT-IR spectroscopy. Journal of Chemical and Pharmaceutical Research. 2014;6(5):796-800.

5. Nataraj K, Duza M, Pragallapati K, et al, Development and validation of RP-HPLC method for estimation of omeprazole in bulk and capsule dosage forms. International Current Pharmaceutical Journal. 2012;1(11):366-369.

6. Khan H, Bandewar S, Zameeruddin M, et al. Development and validation of RP-HPLC method for simultaneous determination of aspirin and omeprazole. Der Pharma Chemica. 2017;9(20):55-58.

7. Kayesh R, Rahman A. Development and validation of RP-HPLC method for quantification of omeprazole in pharmaceutical dosage form. Journal of Scientific Research. 2013;5(2):335-342.

8. Dedania Z, Dedania R, et al, RP-HPLC method for simultaneous estimation of omeprazole and ondansetron in combined dosage form. Asian J Research Chem. 2009;2(2):108-111.

9. Patel R, Patel H, Patel VA, et al. Development and validation of RP-HPLC method for simultaneous determination of omeprazole and diclofenac sodium in capsule dosage form. Journal of Pharmacy Research. 2012;5(3):1640-1642.

10. Sivasubramanian L, Anilkumar V. Simultaneous HPLC estimation of omeprazole and domperidone from tablets. Indian Journal of Pharmaceutical Sciences. 2007;69(5):674-676.

11. Malik T, Ashfaq K. A simple HPLC method for the determination of omeprazole in vitro. International Journal of Pharmaceutical Chemistry. 2012;2(4):126-128.

12. Sharma S, Sahrma M. Development and validation of new analytical methods for simultaneous estimation of drotaverine hydrochloride with omeprazole in pharmaceutical dosage form. Arabian Journal of Chemistry. 2017;10(1):397-403.

13. Jha P, Parveen R, et al, Stability-indicating high performance thin layer chromatographic method for quantitative determination of omeprazole in capsule dosage forms. J AOAC Int. 2010;93(3):787-791.

14. Podilsky G, Berger M, Testa B, et al. Development and validation of an HPLC method for simultaneous monitoring of bromazepam and omeprazole. Journal of Liquid Chromatography \& Related Technologies. 2008;31(6):878-890.

15. Nevado J, Peñalvo G. Simultaneous determination of omeprazole and their main metabolites in human urine samples by capillary electrophoresis using electrospray ionization-mass spectrometry detection. J Pharm Biomed Anal. 2014;92:211-219.

16. Chomistekova Z, Culkova E, Bellova R, et al. Oxidation and reduction of omeprazole on boron-doped diamond electrode: Mechanistic, kinetic and sensing performance studies. Sensors and Actuators B: Chemical. 2017;241:1194-1202.

17. El-Enany N, Belal F, Rizk M. The alternating current polarograhic behaviour and determination of lansoprazole and omeprazole in dosage forms and iological fluids. $J$ Biochem Biophys Methods. 2008;70(16):889-896.

18. Jorge S, Potinha A, Brett AMO. Electrochemical redox behaviour of omeprazole using glassy carbon electrode. Electroanalysis. 2010;22(6):625-631.

19. Shahrokhian S, Ghalkhani M, Bayat M, et al. Voltammetric Behaviour and Determination of Trace Amounts of omeprazole Using an Edgeplane Pyrolytic Graphite Electrode. Iran J Pharm Res. 2015;14(2):465471.

20. El-kommos M, Pankinaz K. A validated spectrofluorometric method for assay of some proton pump inhibitors using sodium 1,2naphtoquinone-4- sulphonate. International Journal of Pharmacy and Pharmaceutical Sciences. 2014;6(5):212-219.

21. Wahbi A, Abdel-Razak O, Gazy AA, et al. Spectrophotometric determination of omeprazole, lansoprazole and pantoprazole in pharmaceutical formulations. J Pharm Biomed Anal. 2002;30(5):11331142 .

22. Nassar M, El-shahat M, Khalil SM, et al. Optimization and validation of spectrophotometric and potentiometric methods for determination of lansoprazole and omeprazole in pure and capsules. Indian Journal of Pharmaceutical Sciences. 2017;79(3):420-430.

23. Bhandage A, Bhosale A, Kasture A, et al. Extractive spectrophotometric determination of omeprazole in pharmaceutical preparations. Tropical Journal of Pharmaceutical Research. 2009;8(5):449-454.

24. Baraka M, El-sadek M. Spectrophotometric determination of Omeprazole via nitrosation reaction. International Journal of Current Pharmaceutical Research. 2014;6(3):54-57.

25. Salama F, El-Abasawy N, Abdel Razeq SA, et al. Validation of Spectrophotometric determination of Omeprazole and pantoprazole sodium via their metal chelates. J Pharm Biomed Anal. 2003;33(3):411421.

26. Rajic K, Novovic D, Marinkovic V, et al. First-order UV-derivative spectrophotometry in the analysis of Omeprazole and pantoprazole sodium salts and corresponding impurities. J Pharm Biomed Anal. 2003;32(4-5):1019-1027. 
27. Javali B, Sravanthi B, Gopi K, et al. Development and validation of UV-Spectrophotometric method for simultaneous estimation of Omeprazole and domperidone in capsule dosage forms. Global Journal of Pharmacy and Pharmaceutical Science. 2017;1(2):1-4.

28. Behera S, Ghanty S, et al, UV-Visible Spectrophotometric Method Development and Validation of Assay of Paracetamol Tablet Formulation. Journal of Analytical \& Bioanalytical Techniques. 2012;3(6): 1-6

29. Coppex L. Derivatives for HPLC analysis. Swizerland: University of Genf; 2000.

30. Merghani S, El-bashir A. Spectrophotometric determination of Ranitidine hydrochloride $(\mathrm{RNH})$ in pharmaceutical formulation using 9- Fluorenylmethyl chloroformate (FMOC-Cl). Asian Journal of Pharmaceutical Research and Development. 2018;6(6):7-14.

31. Catrinck T, Dias A, Aguiar MCS, et al. A Simple and efficient method for derivatization of Glyphosate and AMPA using 9-Fluorenylmethyl chloroformate and Spectrophotometric Analysis. Journal of the Brazilian Chemical Society. 2014;25(7):1194-1199.
32. Gul W, Sajid S, Hamid F, et al. Effect of acidic ph and heat on degradation of omeprazole and esomeprazole. The Pharma Innovation Journal. 2015;4(8):19-21.

33. Alash F, El-bashir A. Development and validation of spectrophotometric methods for the Determination of Mesalazine in Pharmaceutical Formulation. Medicinal Chemistry. 2014;4(3):361-366.

34. Baraka M, El-sadek M, Aziz LMA, et al. Spectrophotometric determination of Omeprazole sodium and Ranitidine hydrochloride using 2,4- dinitrofluorobenzene and 4- chloro-7-nitrobenzen-2-oxa3-diazole 1 accompanied with a kinetic study. American Journal of Current Analytical Chemistry. 2014;1(1):1-21.

35. Liu Y, Xu F, Zhang Z, et al. Analysis of synephrine in Da-cheng-qi decoction by HPLC employing precolumn derivatization with 9Fluorenylmethyl chloroformate. J Chromatogr Sci. 2009;47(10):925930.

36. Mojtaba S, Ghassabian S. Linearity of calibration curves for analytical methods: a review of criteria for assessment of method reliability. 2018. 